\title{
PSICÓLOGOS NA RESIDÊNCIA MULTIPROFISSIONAL EM ATENÇÃO BÁSICA: ESTUDO A PARTIR DE DOCUMENTOS E SUJEITOS
}

\section{Eliza Regina Gomes}

Psicóloga; Universidade do Vale do Itajaí, Brasil.

E-mail: elizargomes20@gmail.com

Aline Mariana Heberle

Psicóloga; Universidade do Vale do Itajaí, Brasil.

\section{Carlos Eduardo Maximo}

Docente do curso de Psicologia; Docente da Residência Multiprofissional em Saúde. Docente do Mestrado em Saúde e Gestão do Trabalho (UNIVALI), Itajaí, Santa Catarina (SC), Brasil.

\section{George Saliba Manske}

Docente do curso de Educação Física. Docente da Residência Multiprofissional em Saúde. Docente do Mestrado em Saúde e Gestão do Trabalho (UNIVALI), Itajaí, Santa Catarina (SC), Brasil.
RESUMO: Este estudo tem como objetivo analisar a formação dos psicólogos na Residência Multiprofissional em Atenção Básica/ Saúde da Família da Universidade do Vale do Itajaí (UNIVALI). Foram realizadas 4 entrevistas com os psicólogos residentes do segundo ano de formação (R2), além de ter sido feita uma análise do projeto pedagógico da residência multiprofissional. A análise dos dados foi realizada com base nas proposições do quadrilátero da formação em saúde. Os resultados indicam uma possibilidade de participação na gestão como forma de melhorar os serviços de saúde prestados. Em relação à atenção à saúde, os resultados apontaram um atendimento pautado no princípio da integralidade. O ensino aparece como uma oportunidade de capacitação para o SUS, oferecendo um espaço para discussão com outros profissionais sobre os campos de atuação. A participação dos psicólogos residentes no processo de controle social é considerada essencial para a modificação da realidade dos serviços de saúde.

PALAVRAS-CHAVE: Psicologia; Educação; Sistema Único de Saúde.

\section{PSYCHOLOGISTS IN MULTIPROFESSIONAL RESIDENCE IN BASIC ATTENTION: STUDY FROM DOCUMENTS AND SUBJECTS}

\begin{abstract}
This paper aims to analyze the training of psychologists in the Multi-Professional Residency in Basic Care / Family Health of the University of Vale do Itajaí (UNIVALI). Four interviews were conducted with the resident psychologists of the second year of training (R2), as well as an analysis of the pedagogical project of the Multi-professional residence was made. The data analysis was performed based on the propositions of quadrilateral for training in health. The results indicate a possibility of participation in the management to improve the health services. Regarding health care, the results indicated a service based on principle of integrality. The teaching appears as an opportunity of qualification for SUS, offering a space for discussion with other professionals on the fields of action. The participation of resident psychologists in the process of social control is considered essential for modification of the reality of the health services.
\end{abstract}

KEY WORDS: Psychology; Education; Unified Health System.

\section{INTRODUÇÃO}

O Sistema Único de Saúde (SUS) é composto por um grupo de ações e serviços em saúde prestado nas esferas públicas federais, 
estudais e municipais, agregando ainda iniciativas privadas como forma de complementar este serviço. A criação desse sistema partiu da Lei no 8.080 , de 19 de setembro de 1990, que zela pelas condições em promoção, proteção e recuperação de saúde, bem como pela organização e funcionamento dos serviços correspondentes ao SUS. Seus princípios e diretrizes são a universalidade, equidade, descentralização, atendimento integral e participação da comunidade (SOUZA; COSTA, 2010).

Por um longo período, o conceito de saúde esteve voltado para o modelo biomédico, segundo o qual um corpo saudável é aquele com ausência de doença. Entretanto, faz-se necessário compreender o sujeito por meio de uma visão mais ampla, considerando não só seu aspecto biológico, mas também o social. Sendo assim, o conceito de saúde deixa de considerar somente a ausência de doença e passa a abranger outros aspectos relacionados às condições de vida determinadas pelas formas de organização social.

Segundo Nepomuceno e Brandão (2011), com o resultado do avanço das políticas públicas de saúde, os saberes e as práticas da psicologia passam a ser cada vez mais requisitados, bem como os de outras categorias profissionais da saúde, requerendo a construção de uma práxis sanitária necessariamente interdisciplinar, na qual os elementos psicológicos tornam-se fundamentais. Entretanto,

[...] para superar as lacunas existentes na interface Psicologia e SUS, a atuação do psicólogo deve estar sintonizada, em um nível macropolítico, com os princípios do SUS (universalidade, integralidade e equidade) e, em um nível micropolítico, apontar os processos de construção de subjetividades dos vários atores envolvidos no trabalho em saúde (BENEVIDES, 2005 apud NEPOMUCENO; BRANDÃO, 2011, p 765).

Nesse sentido, contribuições como as de Mendes et al. (2011) permitem-nos identificar algumas mudanças consideráveis no âmbito da saúde, como a criação de programas de residência multiprofissional em saúde que possibilitem a troca de saberes entre distintos profissionais da área da saúde. As residências multiprofissionais abrem espaço para que os psicólogos possam inserir-se no contexto do SUS, desafiando-os a construir um modo de atuação diferente do modelo médico/paciente, partindo para uma proposta multiprofissional.

As residências multiprofissionais em saúde foram criadas a partir da promulgação da Lei $n^{\circ} 11.129 / 2005$ e são orientadas pelas diretrizes e princípios do Sistema Único de Saúde (SUS) a partir das necessidades e da realidade local e regional, abrangendo profissões da área da saúde, sendo estas: Biomedicina, Ciências Biológicas, Educação Física, Enfermagem, Farmácia, Fisioterapia, Fonoaudiologia, Medicina Veterinária, Nutrição, Odontologia, Psicologia, Serviço Social e Terapia Ocupacional. (Resolução CNS no 287/1998). Nesse sentido, a Universidade do Vale do Itajaí - UNIVALI, tendo como setor responsável o Centro de Ciências da Saúde, desenvolveu o Programa de Residência Multiprofissional em Atenção Básica/Saúde da Família da UNIVALI. O programa visa formar profissionais para atuação em saúde coletiva, trabalhando a saúde e o cuidado integral da população.

A atuação da Psicologia nas redes de saúde pública tem como função primordial a compreensão do indivíduo e do contexto no qual ele está inserido, escutando-o e trabalhando suas potencialidades. Busca aprimorar o olhar sobre esse sujeito, realizando intervenções que estejam interligadas às necessidades e potenciais de saúde da população assistida (NEPOMUCENO; BRANDÃO, 2011). Porém, Dimenstein (1998) reflete que o maior desafio do psicólogo é substituir o paradigma da clínica pelo da saúde pública visando compreender o sujeito e fazer saúde a partir das prioridades dessa população.

Tendo em vista que a inserção do psicólogo nas residências multiprofissionais é algo recente, pretendeu-se por meio dessa pesquisa analisar o processo de formação dos psicólogos na Residência Multiprofissional em Atenção Básica/Saúde da Família da UNIVALI. Através das entrevistas foram respondidos os seguintes questionamentos: caracterização da trajetória de formação, condições de trabalho e formação dos contextos de atuação dos psicólogos residentes, descrição da inserção dos psicólogos residentes no processo de ensino, gestão, atenção à saúde e controle social em seu 
processo de formação profissional. O projeto pedagógico da residência serviu como subsídio para identificar conteúdos e práticas formativas propostas por este documento. Desta forma, nossa proposta visa analisar como tem sido o processo de formação profissional de psicólogos nos programas de residência multiprofissional, demonstrando a sua relevância científica e social.

\section{METODOLOGIA}

Esta pesquisa caracteriza-se por ser uma investigação qualitativa com objetivos exploratórios, tendo como procedimentos metodológicos idas a campo para entrevistas com os residentes da Residência Multiprofissional em Atenção Básica/Saúde da Família e análise dos documentos norteadores da formação desses profissionais. Para a coleta de dados foram realizadas entrevistas com 4 residentes do segundo ano de formação (R2) que atuam nos municípios Itajaí, Brusque, Itapema e Balneário Piçarras. Inicialmente, a pesquisa seria realizada com os 7 residentes do segundo ano de formação (R2), porém apenas 4 deles disponibilizaram-se a participar da pesquisa. Os psicólogos residentes foram convidados via e-mail, sendo contatados também em sala de aula. Após conversa e convite inicial, foram apresentados os objetivos da pesquisa e entregues os Termos de Consentimento Livre (TCLE) aos participantes. As entrevistas foram realizadas nas instalações da UNIVALI, dirigidas com questões abertas e organizadas de acordo com o tema da pesquisa. O processo de análise de dados iniciou com a transcrição literal das falas dos entrevistados e com uma pré-análise, tendo como referência os objetivos de pesquisa propostos. Cabe ressaltar que esta pesquisa foi aprovada pelo Comitê de Ética em Pesquisa (CEP) da instituição na qual foi realizada, sendo aprovado sob o Parecer $\mathrm{n}^{0} 1.363 .722$.

Além da entrevista, também realizou-se uma análise do projeto pedagógico da residência. $\mathrm{O}$ documento do projeto pedagógico foi lido na íntegra e categorizado a partir dos objetivos propostos, levando em consideração o referencial analítico proposto, a saber, "O quadrilátero", de Ceccim e Feuerwerker (2004). O projeto pedagógico da residência foi tomado enquanto uma materialidade cultural que compõe uma rede discursiva e de significados que indica os modos pelos quais a formação dos residentes, neste caso, psicólogos, deve ocorrer, delimitando saberes, propondo estratégias, configurando perfis, delineando conteúdos e carga horária, propondo, em suma, projetos de sujeitos egressos, conformando uma base para que ações de formação profissional possam ser efetivadas.

Após a transcrição das entrevistas e leitura do projeto pedagógico da residência, as categorizações de conteúdos foram indexadas a partir dos marcadores conceituais produzidos por reflexões e proposições de Ceccim e Feuerwerker (2004) no artigo "O quadrilátero da formação para a área da saúde". O quadrilátero da formação divide-se em quatro eixos: ensino, gestão, atenção e controle social. Eles foram utilizados para definir os seguintes blocos de discussão:

- Gestão - a participação no processo de organização do trabalho na saúde;

- Atenção à saúde: a integralidade nas práticas em saúde;

- Ensino: a formação de profissionais para o SUS;

- Controle social: a modificação da realidade dos serviços de saúde. Para diferenciar as falas dos participantes, utilizou-se a letra $\mathrm{E}$ (Entrevistado) seguida de números (E1, E2).

\section{RESULTADOS E DISCUSSÃO}

Ceccim e Feuerwerker (2004) analisam a formação do profissional de saúde com base no quadrilátero da formação, que divide-se em quatro pilares, quas sejam: gestão, atenção à saúde, ensino e controle social. Desta forma, refletem que a formação voltada às noções quadriláteras propõe o desenvolvimento de atendimentos que acolham as necessidades dos usuários e dos serviços de saúde, garantindo um serviço de qualidade e estimulando a participação da população na formulação de políticas de saúde, fazendo com que ela também seja responsável pelo cuidado.

Os autores Ferreira; Fiorini e Crivelaro (2010) refletem sobre a proposta do quadrilátero do Ceccim e 
Feuerwerker e tecem perspectivas para os quatro pilares da formação. Sobre a gestão, Ferreira; Fiorini e Crivelaro (2010) propõem que ela deva estruturar as redes de serviços com a finalidade de atender às demandas do sistema de saúde, garantindo a satisfação dos usuários em relação aos serviços prestados. No que se refere à atenção à saúde, os autores discorrem que o objetivo principal deve ser a construção de novas práticas de saúde que atendam às necessidades dos usuários, considerando os princípios do SUS, a humanização e a participação da sociedade.

Em relação ao ensino, Ferreira; Fiorini e Crivelaro (2010) refletem que a finalidade deve ser a modificação da concepção hegemônica tradicional, centrada no professor e na transmissão do conhecimento, dando lugar a uma concepção construtivista que visa a problematização das práticas e dos saberes, impulsionando a produção de conhecimento nos serviços. Além desses aspectos, os autores sinalizam em relação ao controle social, afirmando que é preciso envolver a população na construção de políticas de saúde, estimulando a participação da sociedade na busca pelos seus direitos, visando a construção de um serviço de saúde de qualidade.

\subsection{GESTÃO: A PARTICIPAÇÃO NO PROCESSO DE ORGANIZAÇÃO DO TRABALHO NA SAÚDE}

A análise do projeto pedagógico da residência indica situações do processo de formação envolvidas com a gestão. Segundo este documento, os residentes tem um papel ativo nas questões relacionadas à gestão, tendo em vista que a estruturação do projeto pedagógico propõe que os residentes façam estágios direcionados à atenção a saúde e a gestão da saúde. Desta forma, o projeto pedagógico indica a divisão dos estágios em três eixos, que são: Estágio em Atenção Básica, Estágio em Gestão da Saúde e Estágio em Atenção Especializada. O projeto pedagógico indica que a organização do Programa de Residência Multiprofissional em Atenção Básica oferece aos residentes a oportunidade de compreender e potencializar uma formação que se comprometa com a defesa dos princípios e das diretrizes do SUS, atendendo às necessidades de saúde da população e propondo a transformação das práticas profissionais dos residentes por meio do trabalho multidisciplinar (UNIVALI, 2015).
Durante as entrevistas, os entrevistados apontaram aspectos positivos e negativos referentes à gestão. Os residentes apontaram que têm a possibilidade de participar da gestão e isso contribui tanto para o processo de trabalho dentro das Unidades de Saúde e ESF quanto para seu processo de formação. Os entrevistados refletem que a participação na gestão possibilitou que ocorressem mudanças no seu modo de pensar e de atuar, oferecendo-lhes oportunidade de criar novas propostas de trabalho e ajudar na mobilização da população para buscar melhorias nos serviços.

A possibilidade de participar da gestão foi apontada pelos entrevistados como um aspecto positivo que contribui para o processo de trabalho dos residentes dentro das unidades de saúde em que estão inseridos, auxiliando-os no seu processo de formação e na busca de melhorias para o serviço de saúde. Tal afirmativa evidencia-se na seguinte fala do E4, quando refere-se à participação das reuniões:

$[\ldots]$ a gente tem ali as nossas reuniões, não só as reuniões de psicólogo, mas tem a reunião que eles chamam também de VAR que é o núcleo de estruturação de ensino. [...] Ele é um núcleo de desenvolvimento do projeto pedagógico da residência, e nessa a gente tem voz ativa, claro, não vai todo mundo, vai um participante só e representante dos residentes e ele leva mais ou menos o que a gente quer, e as nossas reivindicações (E4).

Os entrevistados apontaram nas entrevistas alguns aspectos negativos em relação à gestão e que, na opinião deles, deveriam ser melhorados. Nesse sentido, os entrevistados assinalaram que há dificuldade de planejamento nas unidades de saúde, que há falta de comunicação entre profissionais de saúde, gestão e instituições e que os gestores de algumas unidades de saúde têm dificuldade de aceitar a residência. Além disso, os entrevistados relataram que a própria residência apresentou dificuldades na organização da teoria com as atividades práticas e que houve uma falta de planejamento prévio da residência com os locais que recebem os residentes. Os aspectos apontados pelos entrevistados relacionados à falta de planejamento das unidades de saúde e a falta de comunicação entre a gestão e as instituições nota-se na seguinte fala de E3: 
No município A ainda não tem uma RAPS estruturada, ela é bem dividida, não existe um diálogo, não é uma rede, existe psicólogo no CRAS, CREAS, nos CAPS e na saúde não se conversam, nos serviços não se fazem encaminhamentos sólidos, não se têm protocolos, não se têm nada construído conjuntamente e eu sei que isso é uma falha em vários lugares do país, mas isso é uma dificuldade muito grande [...] (E3).

Aspectos como a organização da rede de serviço nas unidades de saúde e ESF de atuação, o desenvolvimento de novas propostas de transformação das práticas profissionais e a participação dos residentes nas práticas de gestão foram evidenciados nas falas dos entrevistados citadas acima. Sendo assim, compreende-se que as práticas profissionais dos residentes entrevistados vão ao encontro dos conceitos sobre gestão apresentados por autores como Carvalho et al (2012) e Ceccim e Feuerwerker (2004), que destacam que a gestão em saúde tem como finalidade organizar as redes de serviços, considerando a acessibilidade e a satisfação dos usuários. Além disso, a participação na gestão tem como finalidade ordenar políticas de formação, oferecer propostas de transformação das práticas profissionais, assegurar redes de atenção à saúde, sendo que o controle social e a participação popular são essenciais para a qualificação da gestão do SUS e para a reorganização do modo de fazer e atuar dos profissionais da saúde.

Com base na análise do projeto pedagógico e das falas dos residentes entrevistados, refletimos sobre a importância da participação dos residentes no processo de gestão, tendo em vista que tal participação faz-se necessária para uma melhor estruturação dos serviços de saúde. A participação dos residentes na gestão contribuirá para um processo de atenção à saúde mais qualificada, preparada para atender às necessidades dos usuários, respondendo às diretrizes e princípios do SUS.

\subsection{ATENÇÃO À SAÚDE: A INTEGRALIDADE NAS PRÁTI- CAS EM SAÚDE.}

Conforme propõe o projeto pedagógico da residência multiprofissional em saúde, como estratégia pedagógica busca-se trabalhar um novo modelo de atenção à saúde partindo da perspectiva multiprofissional. Como o próprio nome sugere, a perspectiva multiprofissional visa a mobilização das equipes de profissionais da área da saúde para que juntos possam atender à demanda da localidade em que atuam (UNIVALI, 2015).

Dessa forma, o modelo de atenção à saúde atualmente proposto pelo SUS e acatado na residência multiprofissional sugere uma compreensão ampliada de saúde. Por compreensão ampliada de saúde referimonos ao conceito amplo de saúde construído na VIII Conferência Nacional de Saúde de 1986, onde afirma-se que o direito à saúde implica na garantia de condições dignas de trabalho, alimentação, moradia, educação, transporte seguro, lazer, acesso universal e igualitário aos serviços de saúde, direito à liberdade e expressão, bem como a participação da população na organização, gestão e controle dos serviços e ações de saúde (BRASIL, 1986).

Nesse sentido, o projeto pedagógico propõe que a residência multiprofissional deve considerar diversas ações de saúde possíveis de serem mobilizadas na perspectiva da promoção da saúde, prevenção de agravos, recuperação e reabilitação, seguindo a linha da integralidade, onde se busca trabalhar em um sistema articulado em rede, trazendo a Atenção Básica como ordenadora e coordenadora do cuidado, sustentada ainda pelos serviços especializados, hospitalares, farmacêuticos, de apoio diagnóstico, entre outros, que devem seguir a mesma lógica estruturante a partir da integralidade (UNIVALI, 2015). Desta forma, a atenção integral caracteriza-se como aquela que consegue ser resolutiva a todos esses aspectos aqui referidos. Estes aspectos nem sempre se resolvem no âmbito da atenção básica. Por este motivo, a Atenção Básica coloca-se como porta de entrada para rede de atenção e ordenadora do cuidado.

De acordo com os relatos apresentados pelos residentes, por mais que haja toda uma mobilização e forte divulgação dos termos "equipe multiprofissional" e "integralidade", a atenção à saúde do usuário ainda é, por vezes, marcada por um modelo biologicista, conforme podemos identificar na fala do E3:

O nosso modelo é muito médico centrado, mesmo na saúde coletiva a gente percebe que não há uma coletividade, é como se fossem estanques, ainda existe bastante isso, 
e criticamente falando, eu acho que o psicólogo, ele ainda tá atendendo demandas que não são da saúde coletiva (E3).

As reflexões acerca dos enfrentamentos com o modelo biologicista e problemas relacionados à gestão percebidos durante a residência são fatores em constante evidência e que vêm sendo questionados e trabalhados para que se reorganizem e faça-se na prática a prescrição do papel.

Com base nas perspectivas apresentadas pelos entrevistados, bem como nos estudos propostos por Ceccim e Feuerwerker (2004) acerca da integralidade, podemos compreender que a integralidade no atendimento em saúde está diretamente ligada à atenção à saúde. Reflete ainda nas práticas do profissional para com o usuário, como acolhimento, vínculo, autonomia dos usuários e resolutividade da atenção, entendidos como fatores relevantes para a resolução dos limites das práticas tradicionais de saúde.

A pontuação feita por E3 marca um contraponto entre duas práticas de atenção à saúde apresentadas pelos residentes durante as entrevistas, o modelo biomédico e a atenção biopsicossocial. Desta forma, podemos compreender a diferença nas práticas de atenção à saúde em diferentes municípios, considerando o território em que o residente atua.

E1 elucida em sua fala a busca pelo atendimento integral e pela mudança no modo de atuar "[...] quando tu entendes saúde, que não é somente aquela atenção direta à situação orgânica e queixa que o sujeito traz naquele momento que ele chega na Unidade de Saúde, e tu vê que além disso, tu ao mesmo tempo, tu entende que é além disso[...]" (E1).

Considerando as colocações de E1, percebemos que alguns profissionais, como os da residência, buscam e reforçam a ideia de um atendimento integral e não centrado somente na questão biológica do usuário, considerando que a integralidade da atenção à saúde abrange a compreensão de clínica ampliada, conhecimento do território e sua realidade, ações em equipe multiprofissional e transdisciplinar, bem como ações intersetoriais. Dessa forma, para lidar com a saúde de forma integral e humanizada, faz-se necessário que o primeiro nível de atenção conte com equipes verdadeiramente interdisciplinares trabalhando no desenvolvimento de intersetoriais (BOING; CREPALDI; MORE, 2009).

Diante das informações apresentadas no projeto pedagógico e nas entrevistas, compreende-se que a inserção dos psicólogos na residência multiprofissional viabiliza a reflexão desses profissionais sobre os modos de atuação que vêm desempenhando. Oferece aos profissionais a possibilidade de repensar suas práticas, propondo-se a criar novas estratégias que sejam eficazes no atendimento da demanda tanto do SUS quanto da população usuária dos serviços de saúde. Essa criação de novas estratégias articuladas com os princípios e diretrizes do SUS é mediada pelo ensino e pela educação permanente, que serão discutidos a seguir.

\subsection{ENSINO: A FORMAÇÃO DE PROFISSIONAIS PARA O SUS.}

O projeto pedagógico da residência multiprofissional destaca como proposta o estímulo à criação de grupos de educação para a saúde visando a promoção de uma relação de mão dupla entre o saber popular e o saber científico, capacitando os residentes para intervir no processo saúde-doença nos aspectos sociais, epidemiológicos e clínicos (UNIVALI, 2015). O projeto pedagógico propõe, ainda, um trabalho multiprofissional visando integrar os saberes de áreas distintas a fim de ampliar a resolubilidade e avançando na construção da integralidade das ações de saúde.

$\mathrm{O}$ ensino aparece nas entrevistas relacionado tanto ao processo de formação profissional durante a graduação quanto ao processo de formação dentro da residência multiprofissional. Em relação à formação na graduação em Psicologia, os entrevistados apontaram que todos os contatos que tiveram com o SUS e com a inserção em trabalhos multidisciplinares deram-se em decorrência de seu interesse e procura espontânea durante o curso.

Ao referirem-se ao ensino no âmbito da residência multiprofissional, os entrevistados destacaram que percebem algumas falhas no modo como os conteúdos são estruturados e transmitidos, além da dificuldade de alguns residentes de trabalhar multidisciplinarmente e 
de compreender alguns temas propostos nas aulas. Os aspectos relacionados às falhas na estruturação e na transmissão dos conteúdos durante as aulas na residência podem ser confirmadas na seguinte fala:

[...] a gente não tem muita discussão da nossa área aqui, acho que por questão de organização, por ser a primeira turma, eu acho que a gente entende, só que faz falta, então desde o começo a gente teve muito assunto geral, muito assim, que é importante também, mas conteúdo assim, específico, que é importante mesmo acabou ficando um pouco de lado. E até hoje assim, é muito desorganizado em relação a isso, mas a gente também entende que os professores tem uma carga horária pequena e tem outras funções que não na residência né?! (E2).

Por outro lado, os residentes entrevistados refletiram sobre a importância do ensino e da educação em saúde durante a formação na residência, contribuindo não só para a elaboração das ações de saúde, mas também na formação desses residentes. Os entrevistados salientam que o ensino acaba oferecendo-lhes um espaço de discussão e reflexão para que possam ser capacitados e habilitados para lidar com as demandas do SUS que aparecem nos contextos de atuação. Nesse sentido, E1 descreve que a residência torna-se um diferencial, pois, “ [...] ela vem e tenta juntar tudo para tentar fazer uma formação melhor para o SUS, só que já deveria acontecer porque a diretriz é essa. O SUS deveria orientar toda a formação, mas não é isso que acontece, infelizmente".

E4 traz em sua fala um discurso que sinaliza a importância da educação em saúde e do ensino na residência possibilitar uma visão mais ampla sobre $o$ SUS aos residentes, pois assim é possível realizar ações correspondentes aos princípios do SUS. Sendo assim, ele destaca que:

[...] aqui na UNIVALI ela tá sendo uma coisa que estamos começando a construir e a gente não sabe o produto que isso vai dar, mas eu vejo com bons olhos que vai prosperar bastante isso ainda, como é uma coisa nova, muita coisa nova de princípio do SUS que tava meio engasgado, nos profissionais e na população, pessoas que até tinham esquecido que têm direitos, pelo menos a residência tá parecendo que tá resgatando um pouco isso (E4).

Dessa forma, compreende-se que as mudanças ocorridas no setor da saúde em decorrência da Reforma Sanitária e seus avanços têm impactado o SUS de maneira que suas dimensões são direcionadas a fim de efetivar essas mudanças, tanto quando nos referimos às práticas de saúde como no campo da formação profissional (CECCIM; FEUERWERKER, 2004). Os autores Albuquerque et al. (2008) discorrem que a formação dos profissionais da saúde deve ser organizada segundo as necessidades da população, atentando para a importância do trabalho em equipe, do estabelecimento de vínculos e da articulação do serviço com o ensino.

Na perspectiva do ensino, Ceccim e Feuerwerker (2004) destacam a importância de uma reforma na educação atrelada à saúde, onde sejam expostos o atendimento dos interesses públicos no que se refere à formação acadêmico-científica, ética e humanística para o desempenho técnico dos profissionais. Seguindo este mesmo eixo, Albuquerque et al. (2008) refletem que o ensino deve proporcionar um espaço de discussão e reflexão acerca da produção de cuidados e da modificação do modelo assistencial em vigor. Neste sentido, os autores Ceccim e Feuerwerker (2004) destacam a importância de buscar apresentar a produção de conhecimento e promoção de avanços em quatro campos - científico, tecnológico, cultural e prestação de serviços -, considerando a disseminação dos saberes produzidos nos serviços, movimentos sociais e nas práticas populares.

Por meio da análise do projeto pedagógico e das falas dos entrevistados, compreende-se que a educação para a saúde deveria partir do pressuposto da integralidade. Este pressuposto permite compreender a cultura e as práticas sociais como partes do processo de educação. Assim, constitui-se o diálogo para formação de novos conhecimentos capazes de estruturar relações multiprofissionais para melhor organizar os serviços em sua responsabilidade com o cuidado dos usuários. Além disso, compreende-se que o ensino deva produzir um espaço para discussões, reflexões e mobilização dos 
profissionais de saúde para a busca de soluções eficazes para os problemas demandados pela população. Assim, compreende-se a importância da educação permanente para os profissionais de saúde, tendo em vista que ela os auxilia a repensar suas práticas e suas linhas de atuação, baseando-se na construção significativa de saberes, conforme sugere Ferreira; Fiorini e Crivelaro (2010).

No questionamento sobre o ensino, percebese que os entrevistados abordam este aspecto como um espaço de discussão. Fazem reflexões sobre a predominância de uma formação na graduação mais voltada para o modelo clínico e a proposta da residência ser de um trabalho multiprofissional que sirva também para formar profissionais capacitados para atuar no SUS, defendendo seus princípios e diretrizes. Ao discutir as questões relacionadas ao ensino, percebe-se que os residentes entrevistados não remetem informações sobre os conteúdos que são estudados na residência, e sim as possibilidades que o ensino na residência multiprofissional proporciona.

\subsection{CONTROLE SOCIAL: A MODIFICAÇÃO DA REALI- DADE DOS SERVIÇOS DE SAÚDE.}

No que se refere ao controle social, os entrevistados indicaram a falta de participação e inserção dos usuários nos conselhos e nas reuniões e a falta de pertencimento do usuário ao serviço, como um dos aspectos principais para a qualidade do serviço. Os entrevistados salientaram que acreditam que a falta de adesão ao processo de controle social ocorra em decorrência da falta de esclarecimentos por parte da gestão no que se refere às datas e horários que ocorrem os conselhos. Os entrevistados relataram que na maioria das vezes os usuários reclamam do atendimento, do médico e de outros fatores, mas não participam das reuniões, não lutam pelo que acreditam e por mudanças e que, por este motivo, as pessoas não são vistas como quem está correndo atrás dos seus direitos, e sim como quem só reclama do serviço.

Em relação à participação dos residentes no processo de controle social, os entrevistados corroboram que sua participação nos conselhos é importante para exigir mudanças, para propor um novo olhar sobre o processo de atendimento e até mesmo para a ocupação de espaços e posicionamentos para que as mudanças necessárias ocorram. Os entrevistados pontuam que as questões como o estabelecimento de vínculo com a unidade e com os territórios e o auxílio à população também são vistas como um caminho possível ao controle social, pois relataram que, ao estabelecer vínculo com os serviços e com os usuários, os residentes podem auxiliar as pessoas a tomarem todo o processo de saúde como delas.

Além disso, os entrevistados apontam que as suas participações no controle social dentro da residência também são importantes, pois eles têm a possibilidade de trazer o que está acontecendo nas unidades e discutirem o que está sendo alcançado ou não, quais os objetivos da residência estão sendo cumpridos e propor mudanças. Os entrevistados salientam que essa participação contribui não só para o funcionamento do trabalho dentro das unidades e para a configuração do programa de residência multiprofissional, mas também para o processo de formação dos profissionais da saúde, possibilitando a compreensão do que realmente é o SUS e como ele funciona.

Tais aspectos relacionados à participação dos residentes no controle social dentro da própria residência evidenciam-se na seguinte fala:

[...] a nossa inserção aí enquanto
residentes, assim, de modo geral,
não só o psicólogo, é que assim,
também por conta de estarmos em
construção e tudo mais, a residência
ela dá liberdade pra gente falar, "oh,
está acontecendo isso, não está ca-
minhando do jeito que vocês estão
pensando, ta caminhando de outro
jeito", ou seja, está rolando uma
autonomia, que essa autonomia ela
está sendo acolhida [...] (E4).

Ainda em relação à participação na residência e à possibilidade de auxiliar na reconfiguração do programa, E4 descreve a importância de impor-se e participar desse processo:

[...] É muito bacana fazer parte disso também, sabe. É como eu venho dizendo, é desgastante às vezes, mas é muito bom assim, quando tu vê o negócio funcionando. Muitas vezes 
a gente não quer se dispor pra algumas coisas, mas é necessário, e isso a gente aprende enquanto profissional, a gente aprende enquanto ser humano, a gente aprende assim a viver de uma maneira mais participante da sociedade assim, de que a gente ta construindo alguma coisa nova e que as pessoas vão poder usufruir isso por anos e anos, eu penso assim a residência é uma experiência nova que vale a pena ser vivida (E4).

Dentre os aspectos levantados pelos entrevistados relacionados ao controle social, a questão da participação dos usuários foi bastante questionada. Esses questionamentos podem ser confirmados na seguinte fala: "As pessoas, elas reclamam porque não tiveram uma consulta, porque a enfermeira faltou, porque o médico não está, mas elas não têm o hábito de lutar por aquilo que elas acreditam. Por quê? [...]" (E3).

Ainda em relação à falta de participação dos usuários no processo de controle social, E2 indica que:

[...] quando a gente começou a residência que eu comecei a ouvir falar sobre isso, da importância da participação do usuário na conquista do direito, né, e uma forma de conseguir isso é por meio dos conselhos locais né, intermunicipal, e aí com a residência eu me envolvi no conselho local e fui me sentindo frustrada porque não ia ninguém nas reuniões (E2).

Os entrevistados sugerem que possíveis justificativas para a não adesão dos usuários à participação nos conselhos e à busca de seus direitos de melhorias nos serviços prestados podem ocorrer pela falta de informações por parte da gestão a respeito do funcionamento dos conselhos. Tal aspecto evidencia-se na fala de E4 entrevistado:

[...] na participação, vem acontecendo algumas coisas assim que a gente vê que ela não ocorre tanto, pelo menos aqui no município $\mathrm{B}$, ela não ocorre tanto por falta de estimulo da própria gestão mesmo, não divulga direito qual que é a data dos conselhos, não faz muita questão de dizer que existe um e pra que existe, entendeu? É mais pra aprovar algumas coisas que eles já querem aprovar, aí convida ali a galerinha que já ta envolvida que é tipo, normalmente um enfermeiro, alguém de um outro setor lá que também é meio parceiro deles, às vezes pessoas que nem sabem necessariamente porque que tão ali e nessa assim né, a população acaba, é... não tem estímulo nenhum e daí nessa que não tem estímulo não tem adesão (E4).

Em relação à comunicação entre os conselhos de saúde e a população de usuários, Shimizu et al. (2013) refletem que a ausência de articulação dos conselhos de saúde com a população local é um indicador significativo para a compreensão da fragilidade do controle social e para o distanciamento entre conselhos e usuários. Indicam que em decorrência dessa falta de articulação, a população tem uma participação reduzida na formulação de propostas que deveriam contribuir na resolução dos problemas de saúde. Neste sentido, os autores apontam a necessidade de articulação dos conselhos de saúde a fim de fortalecer e estimular a participação da população no controle social, criando uma gestão participativa em saúde.

E3 evidencia em sua fala que, na prática, as questões de controle social não correspondem ao regimento dos conselhos de saúde, em cujas reuniões ele alega que todas as pessoas têm direito de manifestaremse.

\begin{abstract}
A organização não é muito feita, nós da residência estávamos indo sempre nas reunióes que têm dos conselhos municipais de saúde, fomos impedidas de nos declarar, de nos manifestar várias vezes, e isso que tá no regimento que qualquer pessoa podia se manifestar, e ai você vê a configuração de quem trabalha no controle social, nessa questão da participação social, são pessoas ligadas à saúde, geralmente médicos que querem discutir financiamento, é esse o movimento que se faz lá (E3).
\end{abstract}

Já E1 caracteriza a gestão como sendo punitiva, indicando que os servidores em geral não se manifestam por melhorias, pois têm medo de serem punidos. A fala a seguir confirma tal aspecto levantado pela entrevistada: 
Então, a gente se expõe no Conselho bastante, no Conselho de Saúde, se tem alguma coisa que a gente não se agrada, a gente levanta a mão e questiona, coisas que os servidores se eles forem fazer, muitas vezes vão ser meio que, aqui tem uma gestão muito... Como que se diz? Que castiga sabe? É tipo como, se tu fizer alguma coisa e que a gestão não se agrade ela vai te tirar alguma coisa tua pra mostrar que tu não pode mais fazer isso, entende? [...] É uma gestão meio punitiva, então alguns servidores não se sentem a vontade de falar algumas coisas e de cobrar, ou questionar, então a gente enquanto residente têm esse espaço (E1).

O controle social corresponde à participação da população na implantação e na implementação de políticas de saúde, buscando a qualidade dos serviços de saúde prestados. Por meio do controle social, a população usuária, diversos profissionais e representantes do governo podem atuar em diversos aspectos da formulação de estratégias e do controle da execução das políticas de saúde, os quais vão de aspectos econômicos e financeiros até a fiscalização das ações do governo e o cumprimento das leis relacionadas ao SUS. (MINISTÉRIO DA SAÚDE, 2013).

Segundo Rolim; Cruz e Sampaio (2013), o controle social e a participação da população no processo de formulação e controle das políticas públicas de saúde são princípios do SUS que se destacam como de grande importância social e política, pois oferecem à população o direito de decidir e de controlar ações realizadas pelo Estado. Neste sentido, refletimos sobre a importância da participação da população para a modificação das estratégias dos serviços de saúde.

Segundo os regimentos dos conselhos de saúde, a população tem acesso aos conselhos, porém as falas dos entrevistados evidenciam que a população não se faz presente, não busca melhorias, não luta pelos seus direitos e por serviços de melhor qualidade. Em relação à inserção dos psicólogos residentes no controle social, compreendemos, por meio das falas dos entrevistados, que tal inserção contribui para a modificação da realidade dos serviços de algumas unidades, considerando que, segundo os entrevistados os servidores não têm voz para solicitar mudanças. Os residentes mediam essas solicitações nos conselhos de saúde.

As gestões não comunicarem adequadamente os dias e locais dos conselhos, bem como proibirem alguns servidores de se pronunciar foram questões apontadas com grande predominância entre os entrevistados. Sendo assim, paramos para refletir sobre o fato de que, se o controle social deve envolver também a participação dos profissionais e da população, por que alguns são proibidos de pronunciarem-se ou até mesmo não são comunicados sobre as reuniões? O que podemos compreender com tais informações é que, nestes casos, há uma contradição na construção das políticas de saúde, a qual pode ser decorrente dos autores envolvidos defenderem interesses diferentes.

\section{CONCLUSÃO}

A proposta deste estudo foi discutir o percurso formador de psicólogos residentes a fim de analisar o processo de formação profissional dos psicólogos na Residência Multiprofissional em Atenção Básica/Saúde da família da UNIVALI.

Neste sentido, a partir do trabalho desenvolvido levantaram-se evidências sobre a importância de uma formação que atenda não só as necessidades do SUS como também da população usuária dos serviços do sistema. A partir disto, as categorias de análise do presente artigo foram organizadas de acordo com a proposição do "quadrilátero da formação para SUS". Retomar este tema quando já estamos concluindo justifica-se para que possamos propor indicações do percurso formdor dos psicólogos não apenas na residência multiprofissional em saúde da família em questão, como também em relação à base da formação do psicólogo nos cursos de graduação.

A experiência referida pelos psicólogos participantes da pesquisa envolvidos no processo de formação da residência evidencia a importância do contato com a realidade do Sistema Único de Saúde, mediada por conhecimentos que possibilitem implicação e crítica ao modo como as práticas de saúde ofertadas pelo Estado à sociedade brasileira são estabelecidas. Os domínios da gestão, do controle social e do ensino/ 
educação para a saúde produzem tensão frente à clássica formação do psicólogo orientada para o domínio assistencial, fundamentalmente psicoterápico e instrumental, essencialmente avaliativo e classificatório. Mesmo o domínio assistencial passa a ser interpelado pela dimensão de uma lógica assistencial orientada para a integralidade.

Desde 1992, partindo nesta data com "carta de serra negra", setores da psicologia brasileira, articulados por alguns conselhos regionais e universidades, vêm discutindo a formação em Psicologia. Na pauta dos vários eventos que seguiram esteve sempre presente a aproximação com os direitos sociais e as políticas públicas. A experiência retratada neste artigo indica caminhos possíveis para dar conta desta tarefa e provocanos a pensar experiências semelhantes para os cursos superiores de graduação em Psicologia.

\section{REFERÊNCIAS}

ALBUQUERQUE, V.S; GOMES, A.P; REZENDE, C.H.A.D; SAMPAIO, M.X; DIAS, O.V; LUGARINHO, R.M.A integração ensino-serviço no contexto dos processos de mudança na formação superior dos profissionais da saúde. Revista Brasileira de Educação Médica, Rio de Janeiro, v.32, n.3, p.356-362, 2008.

BOING, E.; CREPALDI, M.A.; MORE, C.L.O.Aepistemologia sistêmica como substrato à atuação do psicólogo na atenção básica. Psicologia, ciência e profissão, Brasília, v.29, n.4, p.813-845, 2009.

BRASIL. MEC (Org.). Residência Multiprofissional. 2013. Disponível em: <http://portal.mec.gov.br/ residencias-em-saude/residencia-multiprofissional $>$. Acesso em: 13 maio 2016.

BRASIL. Ministério da Saúde. $\mathbf{8}^{\mathbf{a}}$ Conferência Nacional de Saúde. 1986. Disponível em: < http://conselho.saude. gov.br/biblioteca/relatorios/relatorio_8.pdf $>$ Acesso em: 13 de maio de 2016.

CARVALHO, A.L.B; SOUZA, M.D.F; SHIMIZU, H.E; SENRA, I.M.V.B; OLIVEIRA, K.C.D. A gestão do SUS e as práticas de monitoramento e avaliação: possibilidades e desafios para a construção de uma agenda estratégica. Ciência e Saúde Coletiva, Rio de Janeiro, v.17, n.4, p. 901-911, 2012.

CECCIM, R. B.; FEUERWERKER, L. C. M. O quadrilátero da formação para a área da saúde: ensino, gestão, atenção e controle social. Physis, Rio de Janeiro, v.14, n.1, p. 4165,2004 .

CECCIM, R. B.; FEUERWERKER, L. C. M.. Mudança na graduação das profissóes de saúde sob o eixo da integralidade. Caderno de Saúde Pública, Rio de Janeiro, v.20, n.5, p. 1400-1410, 2004.

DIMENSTEIN, M. D. B. O psicólogo nas Unidades Básicas de Saúde: desafios para a formação e atuação profissionais. Estudos de Psicologia, p.53-81, 1998.

FERREIRA, R. C; FIORINI, V.M.L; CRIVELARO, E. Formação profissional no SUS: o papel da Atenção Básica em Saúde na perspectiva do docente. Revista Brasileira de Educação Médica, v.34, n.2, p. 207-215, 2010.

MENDES, L.C; MATOS, L.D.P; SCHINDLER, M.F; TOMAZ, M.; VASCONCELLOS, S.C. Relato de experiência do primeiro ano da residência multiprofissional hospitalar em saúde, pela ótica da Psicologia. Revista SBPH, v.14, n.1, p.125-141, 2011.

MINISTÉRIO DA SAÚDE, (Brasil). Para entender o controle social na saúde. Ministério da Saúde, Conselho Nacional de Saúde, Brasília: 2013. Disponível em: $<$ http://conselho.saude.gov.br/biblioteca/ivros/Manual_ Para_Entender_Controle_Social.pdf $>$ Acesso em: 10 maio 2016.

NEPOMUCENO, L. B.; BRANDAO, I. R. Psicólogos na estratégia saúde da família: caminhos percorridos e desafios a superar. Psicologia, ciência e profissão. Brasília, v.31, n.4, p.762-777, 2011.

ROLIM, L.B; CRUZ, R.S.B.L.C; SAMPAIO, K.J.AJ. Participação popular e o controle social como diretriz do SUS: uma revisão narrativa. Saúde em Debate, v.37, n.96, p. 139-147, 2013.

SHIMIZU, H.E. PEREIRA, M.F; CARDOSO, A.J.C; BERMUDEZ, X.P.C.D. Representações sociais dos 
conselheiros municipais acerca do controle social em saúde no SUS. Ciência e Saúde Coletiva, v.18, n.8, p.2275-2284, 2013.

SOUZA, G. C. de A.; COSTA, I. do C. C. O SUS nos seus 20 anos: reflexões num contexto de mudanças. Saúde soc. v.19, n.3, p.509-517, 2010.

UNIVERSIDADE DO VALE DO ITAJAI. Centro de Ciências da Saúde. Programa de Residência Integrada Multiprofissional em Atenção Básica/Saúde da Família. Itajaí: Univali, 2015.

Recebido em: 19 de maio de 2017 Aceito em: 06 de agosto de 2017 